\title{
Currency Hedging Between the US Dollar and The Chinese Yuan: A Lead Effect
}

\author{
Gordon Smith \\ Anderson University \\ John W. Frazier \\ Anderson University
}

\begin{abstract}
This study investigates currency hedging over a ten year period between the US Dollar and the Chinese Yuan. A brief review of hedging currency and risk management is provided. Several regressions are performed to determine if there are any variables that would be useful in predicting the future exchange rate between the US Dollar and the Chinese Yuan. The study is limited in the fact that it only examines hedging between two currencies. This study concludes that there are statistically significant variables potentially useful in projecting exchange rate fluctuations between the US Dollar and the Chinese Yuan.
\end{abstract}

Keywords: Risk Management, Exchange Rates, Currency, Hedging

\section{INTRODUCTION}

Businesses are evolving into a more globally focused orientation. As the world's economies become more interrelated, business leaders are increasing looking for ways to mitigate their cross-country risk. In today's global economy, one of the greatest risks faced by decision makers is exchange rate fluctuations. According to Brealey and Myers (1996) most organizations hedge or insure to reduce risk. Hedging is done by a firm or individual to protect against price change that would otherwise negatively affect profits. "If two parties have mirror-image risks, then they can enter into a transaction that eliminates, as opposed to transfers risk...one party to a futures contract could be a speculator, the other a hedger. Thus, to the extent that speculators broaden the market and make hedging possible, they help decrease risk to those who seek to avoid it" (Brigham \& Daves, 2010, p. 856). Craig Hewett (2005) suggests that hedging strategies can vary in complexity, but the motive for using them is typically the same. These motives include locking in future prices of a commodity, interest rate, or exchange rate which are critical to a company's internal cost structure. Miller (2002) looks at the success of using hedging strategies to limit investment loss. He suggests that a working knowledge of hedging strategies is increasing in importance. Miller posits that hedging strategies can be extremely useful in mitigating risk and that organizational leaders should be meticulous in evaluating and utilizing hedge instrument to reduce risk.

Generally, there is a cost to hedging risk, which typically is a zero NPV transaction. Why then should business leaders hedge risk? "It makes financial planning easier and reduces the odds of an embarrassing shortfall...In extreme cases an unhedged setback could trigger financial distress or even bankruptcy" 
(Brealey and Myers, 1996, p. 707). Managers are not compensated to avoid all risks; however, if they can reduce their exposure to some types of risk they may place larger bets when the odds are in their favor. Forward contracts are one of the main tools utilized to hedge against foreign currency risk. "There is a huge volume of business in forward currency. In 1992 the total value of outstanding forward contracts was $\$ 5.5$ trillion and the annual turnover was more than 10 times this figure" (Brealey and Myers, 1996, p. 717). More recently, at the end of June 2017, the gross market value of outstanding OTC derivatives contracts fell below $\$ 13$ trillion, its lowest level since 2007 (Statistical release: OTC derivatives statistics at end-June 2017, 2017, p. 2).

Much has been made with regard to trade with China. Greater trade volume between the U.S. and China has created a greater emphasis risk-hedging in the currency markets between the U.S. dollar and the Chinese Yuan. An example of hedging as a risk-reducing agent could be as follows: An organization that is an importer of Chinese goods could reduce its currency risk by purchasing derivative contracts that increase in value whenever the dollar depreciates. This would have the goal of reducing risk exposure to an organization's net income (Brigham \& Daves, 2010). The focus of this paper is to provide a useful approach to business managers looking to mitigate risk thorough the potential use of hedging contracts. The data utilized in the paper may provide insight into lead variables that may signal a potential shift in the exchange rate between the U.S. and China. These variables could be used as one tool within an organization's overall hedging strategy.

\section{REVIEW OF RELATED LITERATURE}

There have been many studies that have attempted to examine and predict hedging strategies relative to currency exchange rate. Black (2018) examined currency hedging in an effort to provide business decision makers with a potential formula for mitigating risk associated with exchange rates. She hypothesized that the Chinese U.S. exchange rate is a function of several different factors. Included in these factors are the U.S. 10-year Treasury bond, the U.S. interest rate, the U.S. CPI, the Chinese CPI, the Chinese government bond rate and the Chinese Import Price Index. Black used multiple regression to determine if there was a relationship between the hypothesized variables and the Chinese U.S. exchange rate. The study concluded that the U.S. CPI and the Chinese Import Price Index were statistically significant predictor variables of the Chinese U.S. exchange rate.

Frazier (2014) examined a US automotive manufacturer's hedging strategy relative to currency fluctuation associated with supplied product from Canada. Frazier hypothesized that the Canadian U.S. exchange rate is a function of the U.S. 10-year Treasury bond, Canadian 10-year government bond, the U.S. interest rate, the Canadian CPI, and the U.S. CPI. Stepwise regression analysis was utilized to determine the effect of the different variables on the U.S. Canadian exchange rate. Frazier's analysis of the automotive manufacturer's case study revealed that the U.S. CPI, the U.S. 10-year Treasury bond, and the Canadian 10-year government bond were all statistically significant predictor variables of the Canadian U.S. exchange rate.

Chung (2009) employed a time series model to determine the hedging performance of metals and fuel oil futures traded on the Shanghai futures exchange. The main goal of his work was to examine the performance of different models with regard to their ability to decrease variance within hedge portfolios and test for statistical significance of the performance gains of these models. The results of the study suggested that including the long-term memory effects on the spot returns and futures market offers a better explanation of the dynamic behavior around the commodity prices and demonstrates a statistically significant role in improved hedge performance.

Myoung (2010) studied the correlation between exchange rate fluctuations and hedging activity. He concluded that currency hedging sometimes is good to do when the right tools are available to measure the movements in future currency prices.

Zakamouline (2009) explored hedging strategies which included transaction costs. The central focus of the study was to examine different hedging strategy alternatives as well as the type of option position being hedged. The risk propensity of the individual performing the hedge was also taken into account. 
The aim of the study was to attempt to offer an optimization method for the improvement of the hedging strategies. The results of the study indicate that the ranking of the alternative strategies by the individual considering a hedging strategy is a function of the individual's propensity for risk and the potential makeup of the option's payoff.

Frestad (2009) studies the efficiency of different hedging strategies of firms that are facing price risk. The investigation suggests that for most firms' variance minimizing hedging strategies closely mirror value maximizing hedging strategies. The study determined that linear hedging strategies generally are efficient in reducing risk. However, a concern acknowledged by Frestad was that most of the firms in the study used linear hedging strategies even though their price risk exposure was nonlinear.

Fisher and Kumar (2010) attempted to determine the appropriate method for hedging. They suggested that there were strategic, financial, and operational benefits to hedging risk. Additionally, Fisher and Kumar recognized that when done inappropriately, hedging can create a larger issue and cause a firm to lose more value than was originally at risk. They posited that risk managers ought to examine both the total cost and total benefits of hedging and only hedge what really matters. They suggested that only exposure that poses a risk to the organization's strategic plan or the firm's financial health should be hedged. Finally, Fisher and Kumar indicated that risk managers should quantitatively test the effectiveness of differing strategies and compare the cost benefit analysis of each option prior to settling on a particular strategy.

\section{METHODOLOGY AND DATA}

The basic methodological approach of this paper was to identify a set of relatively straightforward variables which could be helpful to managers in the decision-making process regarding a hedging strategy in relation to the China U.S. exchange rate. In order to evaluate the variables affecting the China U.S. exchange rate, two primary factors were considered; price level and interest rates. Two methods were considered, regressing level data and regressing percentage change data.

All data was monthly and not seasonally adjusted. All data was retrieved from the St. Louis Federal Reserve Bank database (FRED), except for the 1-year, 5-year, and 10-year Chinese government bond yields, which were retrieved from Investing.com. The data were for the months between January 2013 and December 2017, inclusive. The data reflect end-of-month observations. Monthly percentage changes reflect the change from the previous end-of-month to the current end-of-month. 
TABLE 1

DESCRIPTION OF KEY VARIABLES

\begin{tabular}{|l|l|}
\hline Abbreviation & Variable \\
\hline China-US ER & $\begin{array}{l}\text { Nominal China-U.S. exchange rate } \\
\text { Chinese Yuan to one U.S. dollar }\end{array}$ \\
\hline China-US CPI & $\begin{array}{l}\text { China-U.S. CPI ratio } \\
\text { China - all items, index 2015 = 100 } \\
\text { U.S. - all items, all urban consumers, index 1982-1984 =100 }\end{array}$ \\
\hline Spread 1Y & $\begin{array}{l}\text { Spread between yields on 1-year China and U.S. government bonds } \\
\text { Chinese percentage point yield minus U.S. percentage point yield }\end{array}$ \\
\hline Ratio 1Y & $\begin{array}{l}\text { China-U.S. 1-year government bond yield ratio } \\
\text { Chinese percentage point yield to one percentage point U.S. yield }\end{array}$ \\
\hline Spread 5Y & $\begin{array}{l}\text { Spread between yields on 5-year China and U.S. government bonds } \\
\text { Chinese percentage point yield minus U.S. percentage point yield }\end{array}$ \\
\hline Ratio 5Y & $\begin{array}{l}\text { China-U.S. 5-year government bond yield ratio } \\
\text { Chinese percentage point yield to one percentage point U.S. yield }\end{array}$ \\
\hline Spread 10Y & $\begin{array}{l}\text { Spread between yields on 10-year China and U.S. government bonds } \\
\text { Chinese percentage point yield minus U.S. percentage point yield }\end{array}$ \\
\hline Ratio 10Y & $\begin{array}{l}\text { China-U.S. 10-year government bond yield ratio } \\
\text { Chinese percentage point yield to one percentage point U.S. yield }\end{array}$ \\
\hline Ratio 5-1 S & $\begin{array}{l}\text { Ratio of the spread between Chinese 5-year and 1-year government bond yields } \\
\text { to the spread between U.S. 5-year and 1-year government bond yields }\end{array}$ \\
\hline Ratio 10-5 S & $\begin{array}{l}\text { Ratio of the spread between Chinese 10-year and 5-year government bond } \\
\text { yields to the spread between U.S. 10-year and 5-year government bond yields }\end{array}$ \\
\hline Ratio 10-1 S & $\begin{array}{l}\text { Ratio of the spread between Chinese 10-year and 1-year government bond } \\
\text { yields to the spread between U.S. 10-year and 1-year government bond yields }\end{array}$ \\
\hline
\end{tabular}

Initially, two tests were run. The first test regressed the China U.S. exchange rate based on a percentage change approach. This test failed to show much promise either from an explanatory or a statistical value. The second test regressed the China U.S. exchange rate from a level approach. This test generated much better results and was the approach used for the statistical model.

Once the overall approach was determined, the complete set of level data was regressed against the China U.S. exchange rate (Test 1). Afterwards, the data was broken down between spread data (Test 2) and ratio data (Test 3 ). These separate constructions were regressed in a number of different combinations with the exchange rate. From these results, those variables which showed the greatest explanatory promise were regressed in different combinations to develop the best explanatory model (Test 4).

\section{RESULTS}

\section{Test 1}

In the initial test, the complete set of data, both ratio and spread data, were regressed against the China U.S. exchange rate. 
TABLE 2

INITIAL TEST

\begin{tabular}{lccccc}
\hline & Coefficients & Standard Error & $t$ Stat & P-value & Significance \\
\hline Intercept & 6.523616 & 3.178138 & 2.052654 & 0.045467 & \\
China-US CPI & 2.478687 & 7.845402 & 0.315941 & 0.753389 & \\
Spread 1Y & -0.62471 & 0.184054 & -3.39414 & 0.001372 & $* * *$ \\
Ratio 1Y & 0.001909 & 0.006227 & 0.30654 & 0.760493 & \\
Spread 5Y & 0.578872 & 0.296836 & 1.950139 & 0.056893 & $* *$ \\
Ratio 5Y & -0.25965 & 0.118794 & -2.18569 & 0.033647 & $* *$ \\
Spread 10Y & -0.22035 & 0.317825 & -0.69331 & 0.491389 & \\
Ratio 10Y & 0.308081 & 0.429675 & 0.717009 & 0.476773 & \\
Ratio 5-1 S & 0.710857 & 0.480492 & 1.479435 & 0.145425 & \\
Ratio 10-5 S & 1.042818 & 0.381772 & 2.731517 & 0.00874 & $* * *$ \\
Ratio 10-1 S & -2.56725 & 0.806868 & -3.18175 & 0.002541 & $* * *$ \\
& & & & & \\
R-squared $=0.790$ & & & & & \\
\hline
\end{tabular}

The $F$-statistic for the model was 18.34 , indicating as a whole the model was statistically significant, and the R-squared was 0.79 . In terms of the independent variables, the 1-year and 5-year spreads were statistically significant, as well as the 5-year ratio. In addition, the ratio of 10-5 and 10-1 year spreads were also significant.

A second test was run in which the independent variables were regressed as one month leads to the following month's exchange rate.

TABLE 3

INITIAL TEST (ONE MONTH LEAD)

\begin{tabular}{lccccc}
\hline & Coefficients & Standard Error & $t$ Stat & P-value & Significance \\
\hline Intercept & 7.444833 & 3.104959 & 2.397723 & 0.020436 & \\
China-US CPI & 0.39242 & 7.642887 & 0.051345 & 0.959264 & \\
Spread 1Y & -0.61012 & 0.179943 & -3.39061 & 0.001403 & $* * *$ \\
Ratio 1Y & 0.002259 & 0.006048 & 0.373585 & 0.710358 & \\
Spread 5Y & 0.572353 & 0.288318 & 1.985146 & 0.052858 & $* *$ \\
Ratio 5Y & -0.2834 & 0.115387 & -2.45608 & 0.017716 & $* * *$ \\
Spread 10Y & -0.26203 & 0.313646 & -0.83542 & 0.407619 & \\
Ratio 10Y & 0.301307 & 0.422667 & 0.712871 & 0.479377 & \\
Ratio 5-1 S & 0.752667 & 0.467283 & 1.61073 & 0.113796 & $* * *$ \\
Ratio 10-5 S & 1.062546 & 0.374861 & 2.834505 & 0.006696 & $* * *$ \\
Ratio 10-1 S & -2.46991 & 0.787511 & -3.13635 & 0.00292 & $* *$ \\
& & & & & \\
R-squared $=0.804$ & & & & & \\
\hline
\end{tabular}

The predictability of this model improved slightly (R-squared $=0.804)$ over the previous non-lead model with all the coefficients retaining their respective signs and the 5-year ratio gaining in significant. 
One significant change of note was the coefficient for the China U.S. CPI. Though not statistically significant in either model, which was somewhat surprising, there was also a significant decline in its value between the two models, from 2.48 in the non-lead model to 0.39 in the 1-month lead model.

\section{Tests 2 and 3}

The second test broke the explanatory variables out into those constructed as ratios and those constructed as spreads. In addition, in light of the results from the first test, and in view of the PPP model, the second test started with a regression of the exchange rate against the CPI ratio. This initial test produced an R-squared of 0.429 and .01 level of significance for the CPI ratio. However, further tests which included either the ratio or spread data on the government bond yields reduced the explanatory value of the CPI ratio and, in some cases, eliminated its statistical significance altogether.

For the spread data, the highest R-squared values for non-lead data was produced from models with the CPI ratio and the 1-year and 5-year spread data, respectively. The multiple $\mathrm{R}$ and R-squared for these models ranged from 0.733 to 0.766 for the multiple $\mathrm{R}$ and 0.538 to 0.588 for the R-squared. Using a 1month lead improved these results for R-squared by 2-6 basis points.

\section{TABLE 4}

TEST 2 (ONE MONTH LEAD, 1 YEAR SPREAD)

\begin{tabular}{lccccc}
\hline & Coefficients & Standard Error & $t$ Stat & P-value & Significance \\
\hline Intercept & 0.303175 & 3.457419 & 0.087688 & 0.930437 & \\
China-US CPI & 15.77305 & 8.01261 & 1.968528 & 0.053965 & $* *$ \\
Spread 1Y & -0.21018 & 0.047157 & -4.45709 & $4.03 \mathrm{E}-05$ & $* * *$ \\
& & & & & \\
R-squared $=0.594$ & & & & \\
\hline
\end{tabular}

TABLE 5

TEST 2 (ONE MONTH LEAD, 5 YEAR SPREAD)

\begin{tabular}{lccccc}
\hline & Coefficients & Standard Error & $t$ Stat & $P$-value & Significance \\
\hline Intercept & 1.097434 & 3.073542 & 0.357058 & 0.72239 & \\
China-US CPI & 14.0831 & 7.122957 & 1.977142 & 0.052956 & $* *$ \\
Spread 5Y & -0.32913 & 0.059075 & -5.57135 & $7.49 \mathrm{E}-07$ & $* * *$ \\
& & & & & \\
R-squared $=0.646$ & & & & \\
\hline
\end{tabular}

Moving to the ratio data, the regressions produced slightly higher R-squared values (versus the spread data) for both non-lead and 1-month lead data. Once again, the 1-month lead data approach explained more of the exchange rate variation than the non-lead data. In comparison to the spread data, the 1-month lead on the 1-year ratio between bond yields produced the best results, followed by the 5-year ratio. 
TABLE 6

TEST 3 (ONE MONTH LEAD, 1 YEAR RATIO)

\begin{tabular}{lccccc}
\hline & Coefficients & Standard Error & $t$ Stat & P-value & Significance \\
\hline Intercept & 5.062454 & 3.46047 & 1.462938 & 0.149075 & \\
China-US CPI & 3.764187 & 8.154357 & 0.461617 & 0.646144 & \\
Ratio 1Y & -0.01608 & 0.00272 & -5.91201 & $2.11 \mathrm{E}-07$ & $* * *$ \\
& & & & & \\
R-squared $=0.662$ & & & & \\
\hline
\end{tabular}

TABLE 7

TEST 3 (ONE MONTH LEAD, 5 YEAR RATIO)

\begin{tabular}{lccccc}
\hline & Coefficients & Standard Error & $t$ Stat & P-value & Significance \\
\hline Intercept & -5.53997 & 2.91632 & -1.89964 & 0.062634 & \\
China-US CPI & 29.35981 & 6.783644 & 4.328029 & $6.27 \mathrm{E}-05$ & $* * *$ \\
Ratio 5Y & -0.17245 & 0.049723 & -3.4682 & 0.001015 & $* * *$ \\
& & & & & \\
R-squared $=0.548$ & & & & \\
\hline
\end{tabular}

Finally, regressions were also run on the ratio of spreads between the various yields (Ratio 5-1 S, Ratio 10-5 S, and Ratio 10-1 S). Though based on the $F$-statistic, these models were all statistically significant and produced R-squared values in the 0.45 range, the ratio of the spreads were statistically insignificant. The primary value of these models came from the China U.S. CPI ratio.

\section{Test 4}

Based on the results from all the previous tests, five variables were chosen as the best potential predictors for future movements in the China U.S. exchange rate: the 1-month lead on the China U.S. CPI ratio, the 1-month lead on the 1-year and 5-year ratios, and the 1-month lead on the 1-year and 5-year spreads. The initial model used all five variables together. Though the model was statistically significant with a relatively high R-squared (0.716), it produced statistically insignificant results for all the independent variables except for the 1-year ratio.

Taking this as a cue, a simple regression was run using the 1-month lead on the 1-year ratio.

TABLE 8

TEST 4 (ONE MONTH LEAD, 1 YEAR RATIO)

\begin{tabular}{lccccc}
\hline & Coefficients & Standard Error & t Stat & P-value & Significance \\
\hline Intercept & 6.659795 & 0.032038 & 207.8721 & $8.59 \mathrm{E}-84$ & \\
Ratio 1Y & -0.01708 & 0.001623 & -10.5257 & $5.56 \mathrm{E}-15$ & $* * *$ \\
& & & & & \\
R-squared $=0.660$ & & & & \\
\hline
\end{tabular}

From this point, a progressive stepwise additive approach was taken to determine the best fit of efficiency, predictability, and statistical significance using different combinations of the other four 
variables with the 1-year ratio. The best fit proved to be a combination of the 1-year and 5-year ratios. The results of the final model are below.

TABLE 9

TEST 4 (ONE MONTH LEAD, 1 AND 5 YEAR RATIO)

\begin{tabular}{lccccc}
\hline & Coefficients & Standard Error & $t$ Stat & $P$-value & Significance \\
\hline Intercept & 6.877159 & 0.084481 & 81.40499 & $7.55 \mathrm{E}-60$ & \\
Ratio 1Y & -0.01414 & 0.001872 & -7.55268 & $4.22 \mathrm{E}-10$ & $* * *$ \\
Ratio 5Y & -0.11339 & 0.041133 & -2.75672 & 0.007867 & $* * *$ \\
& & & & & \\
R-squared $=0.701$ & & & & \\
\hline
\end{tabular}

The test for multicollinearity resulted in satisfactory values (below 2.00 for each independent variable). However, one issue that did arise was autocorrelation, which tends to arise when using time series data. The test for autocorrelation resulted in a Durbin-Watson statistic of 0.23 . This is below the lower-bound of the satisfactory range for no autocorrelation. While OLS models are robust enough to handle the issue of autocorrelation (Berry and Feldman, 1985), two alternative approaches were used to try to ameliorate the problem. An independent variable for the time period was added, as well as running the model on first-differences. Neither of these approaches produced results which were better than the model as it was, so these alternative approaches were set aside.

In the end, the final model predicts that a 1-unit increase in the ratio of 1-year government bond yields will produce a 0.01-unit decrease in the following-month China U.S. exchange rate, and a 1-unit increase in the ratio of 5-year government bond yields will produce a 0.11 -unit decrease in the followingmonth China U.S. exchange rate. Both these predictions make sense in that, as the difference between Chinese and U.S. government bond yields widen, there should be the expectation of an appreciation of the Yuan against the dollar as investor take advantage of the relatively higher Chinese bond yields.

\section{CONCLUSION}

The main focus of this paper was to produce a relatively simple model that could be used by decisionmakers as it relates to an organization's hedging strategy. It was not to create a model that would explain all the variables that could potentially impact the future movements in the China U.S. exchange rate. In this regard, the model meets this criteria. The access to the data and efficiency of the model provide a relatively straightforward way for decision makers to assess potential risks that may arise in the Yuandollar currency exchange market. Going forward, it would be interesting to see if the model is portable to other exchange rates. In addition, employing more sophisticated modeling techniques may also prove valuable, but the results from those techniques will need to be weighed against the simplicity and ease of use of the current modeling technique and structure in place. 


\section{REFERENCES}

Black, M. (2018). Hedging Against U.S. Chinese Currency Fluctuation. Journal of Applied Business and Economics, 20(9), 10-19.

Berry, W., \& Feldman, S. (1985). Multiple regression in practice. Sage Publications, Beverly Hills.

Bodie, Z., Kane, A., \& Marcus, A. (2014). Investments, $10^{\text {th }}$ ed. New York: McGraw-Hill Education.

Brealey, R., \& Myers, S. (1996). Principles of corporate finance. $5^{\text {th }}$ ed. New York: McGraw-Hill.

Brigham, E., \& Daves, P. (2010). Intermediate Financial Management, $10^{\text {th }}$ ed. Ohio: South-Western Cengage Learning.

Chung, S. (2009). Out-of-sample hedge performance for risk management in China commodity futures markets. Asian Economic Journal, 23(3), 349-372.

Fisher, B., \& Kumar, A. (2010). The right way to hedge. McKinsey Quarterly, (4), 97-100.

Frazier, J. (2014). Hedging currency in the automotive industry: a manufacturing case study. International Journal of Business, Accounting, \& Finance, 8(1), 149-159.

Frestad, D. (2009). Why firms choose linear hedging strategies. The Journal of Financial Research, $32(2), 157-167$.

Hewitt, C. (2005). The basics of hedging. Plastics Bulletin, 12-16.

Miller, M. A., (2002). Hedging strategies for protecting appreciation in securities and portfolios. FPA Journal. Retrieved from http://spwfe.fpanet.org.

Myoung, S. C. (2010). Currency risks hedging for major and minor currencies: constant hedging versus speculative hedging. Applied Economics Letters, 17(3), 305-311.

Statistical release: OTC derivatives statistics at end-June 2017. (2017). Retrieved from https://www.bis.org/publ/otc_hy1711.pdf

Zakamouline, V. (2009). The best hedging strategy in the presence of transaction costs. International Journal of Theoretical and Applied Finance, 12(6), 833-860. 